\title{
POTENSI TIMAH PRIMER DAERAH NYELANDING BERDASARKAN ANALISIS DATA GEOMAGNET
}

\author{
Nandito Andrian ${ }^{\mathrm{a}}$, Mardiah $^{\mathrm{a}}$, Irvani $^{\mathrm{a}}$ \\ a Jurusan Teknik Pertambangan, Universitas Bangka Belitung, Balunijuk, Pangkalpinang, 33172, Indonesia
}

\section{ARTICLE INFO}

\section{Article history:}

Received: 17 April 2020

Accepted: 25 June 2020

Available Online: 10 July 2020

\section{Keywords:}

Geomagnetic; Nyelanding; Tin

\section{Corresponding author:}

Mardiah

Jurusan Teknik Pertambangan,

Universitas Bangka Belitung,

Pangkalpinang, Indonesia

Email: mardiahgeo00@gmail.com

\begin{abstract}
The village area of Nyelanding is estimated that there are still many regions that have primary tin prospects, this is confirmed by the large number of community mines that are still operating. This research purposes to see the distribution of primary tin mineralization and zones where deposition of tin. This research uses a geomagnetic exploration survey method with back - rover (mobile) system, the length of the track of $\pm 3.5 \mathrm{~km}$. The spacing of $200 \mathrm{~m}$ as many as 44 tracks, the direction of the track from south to north with data collection techniques starting from west to east. The data obtained of a magnetic strength value which will then be interpreted into a magnetic anomaly map to determine the location of recommendations. The research method used the Geomagnetic Survey method, of GSM-19 T Magnetometer. The interpretation results, the final map with the lowest magnetic anomaly shows magnetic anomaly values ranging from -7.2 to $-3.3 \mathrm{nT}$ at locations $1,2,3$, the highest magnetic anomaly ranges from -4.6 to $5.0 \mathrm{nT}$ in the southern part which is an area close to community settlements and the village highway of Nyelanding, and the direction of mineral distribution for zone 1 starts from east-west, zone 2 focuses towards the middle which means from southwest-northeast direction or vice versa, zone 3 from southwest-northeast. The upward continuity map 250 and matching the location of samples containing Sn levels around the recommended zone, it is certain that the area has cassiterite minerals in the zone namely zone $1=\left(342.760 \mathrm{~m}^{2}\right)$, zone $2=\left(4001.770 \mathrm{~m}^{2}\right)$, zone $3=\left(372.876 \mathrm{~m}^{2}\right)$.
\end{abstract}

Copyright $(2020$ JGEOSREV-UNG This open access article is distributed under a Creative Commons Attribution (CC-BY) 4.0 International license

\section{Pendahuluan}

Timah Primer merupakan endapan timah yang belum mengalami pelapukan, umumnya berbentuk urat - urat polimetalik. Desa Nyelanding banyak terdapat penambangan timah milik masyarakat yang lokasinya tidak luas tetapi banyak dan setempat-setempat. Menurut Hosking (1988), mayoritas endapan timah ditemukan melimpah berasosiasi dengan granit tipe-S dan sangat sedikit dengan granit Tipe-I. Kasiterit (bijih timah) di Pulau Bangka terdapat dua jenis mineralisasi yaitu endapan kasiterit aluvial/sekunder dan endapan kasiterit primer (Sudrajat, 1996). Timah primer terdapat pada endapan greisen, yang merupakan agregat granoblastik dari kuarsa dan muskovit dengan sejumlah mineral asesoris seperti topas, turmalin dan florit yang dibentuk oleh ubahan metasomatik post-magmatik granit (Stemprok, 1987). Daerah penelitian terdiri dari dua formasi yaitu Formasi Tanjung Genting dan Formasi Granit Klabat, dengan litologi tersusun oleh batupasir, batulempung, sedangkan Formasi Granit Klabat tersusun intrusi granit.

Identifikasi cadangan mineral di daerah Desa Nyelanding yang terdahulu menafsirkan cadangan dangkal dengan kedalaman maksimal 3 meter. Penelitian awal oleh geologist PT Timah tbk menyebutkan ditemukannya sebuah singkapan di daerah tersebut yang berupa singkapan urat bijih timah primer, namun belum diketahui kemana arah penyebaran struktur urat tersebut. 
Berdasarkan latar belakang tersebut, rumusan masalah yang diambil yaitu bagaimana menginterpretasikan kondisi di lapangan secara aktual dengan menggunakan data geologi di daerah penelitian. Pengintrepetasian penentuan arah sebaran pola anomali magnetik dan hasil pemetaan zona keterdapatan mineral cassiterite di daerah penelitian. Menentukan daerah potensi zona mineralisasi cassiterite beserta luasan daerahnya. Menurut Margono et al., (1995) bahwa struktur geologi sesar, lipatan, dan kelurusan teramati di Lembar Bangka Selatan. Kelurusan terutama pada granit dengan arah beragam dan lipatan terdapat pada satuan batupasir dan batulempung. Kemiringan lapisan antara 18-75 ${ }^{\circ}$ pada Formasi Tanjung Genting dan Formasi Ranggam.

Metode geofisika saat ini sudah umum digunakan dalam eksplorasi endapan timah primer di Pulau Bangka, salah satu metode yang digunakan adalah geomagnet dimana metode geofisika ini menggunakan sifat kemagnetan bumi. Parameter deklinasi (D) dan inklinasi (I) merupakan parameter yang menggambarkan arah medan magnetik diukur dalam derajat. Intensitas medan magnetik total (F) digambarkan dengan komponen horizontal $(\mathrm{H})$, komponen vertikal $(\mathrm{Z})$ dan komponen horizontal ke arah utara (X) dan ke arah timur (Y) (Telford, 1979).

Daerah mineralisasi memiliki nilai RTE berkisar antara $-44.7-13.1 \mathrm{nT}$ dari 5 baris survei geomagnetik. Nilai RTE adalah hasil dari komponen intensitas magnet yang diduga terkait dengan batuan yang memiliki sifat kerentanan magnetik tinggi dan rendah di lokasi pengukuran pada penelitian di Bukit Sambunggiri (Guskarnali \& Mardiah, 2018). Hasil analisis jarak antar titik pengukuran metode geomagnetik dengan pendekatan metode geostatistik menyimpulkan jarak efektif antara titik pengukuran adalah 40 meter dengan tingkat kepercayaan data yang dihasilkan adalah 0,529 lebih tinggi dari jarak yang lain (Guskarnali \& Mardiah, 2019). Penelitian ini mengamati data geofisika,untuk menentukan arah penyebaran vein, yaitu dengan melakukan pembacaan nilai magnetik batuan dan mineral untuk mengetahui daerah yang terdapat anomali magnetik. Data hasil pembacaan tersebut menjadi referensi awal untuk pengambilan data geolistrik ataupun data geofisika lainnya. Tujuan penelitian ini untuk melihat distribusi mineralisasi timah primer dan zona tempat pengendapan timah.

\section{Metode}

\subsection{Lokasi penelitian}

Lokasi penelitian dilakukan di daerah Desa Nyelanding Kecamatan Air Gegas Kabupaten Bangka Selatan yang terletak pada koordinat UTM 48 S x 641521.63 m (E), Y 9701419.46 m (Y). Lokasi

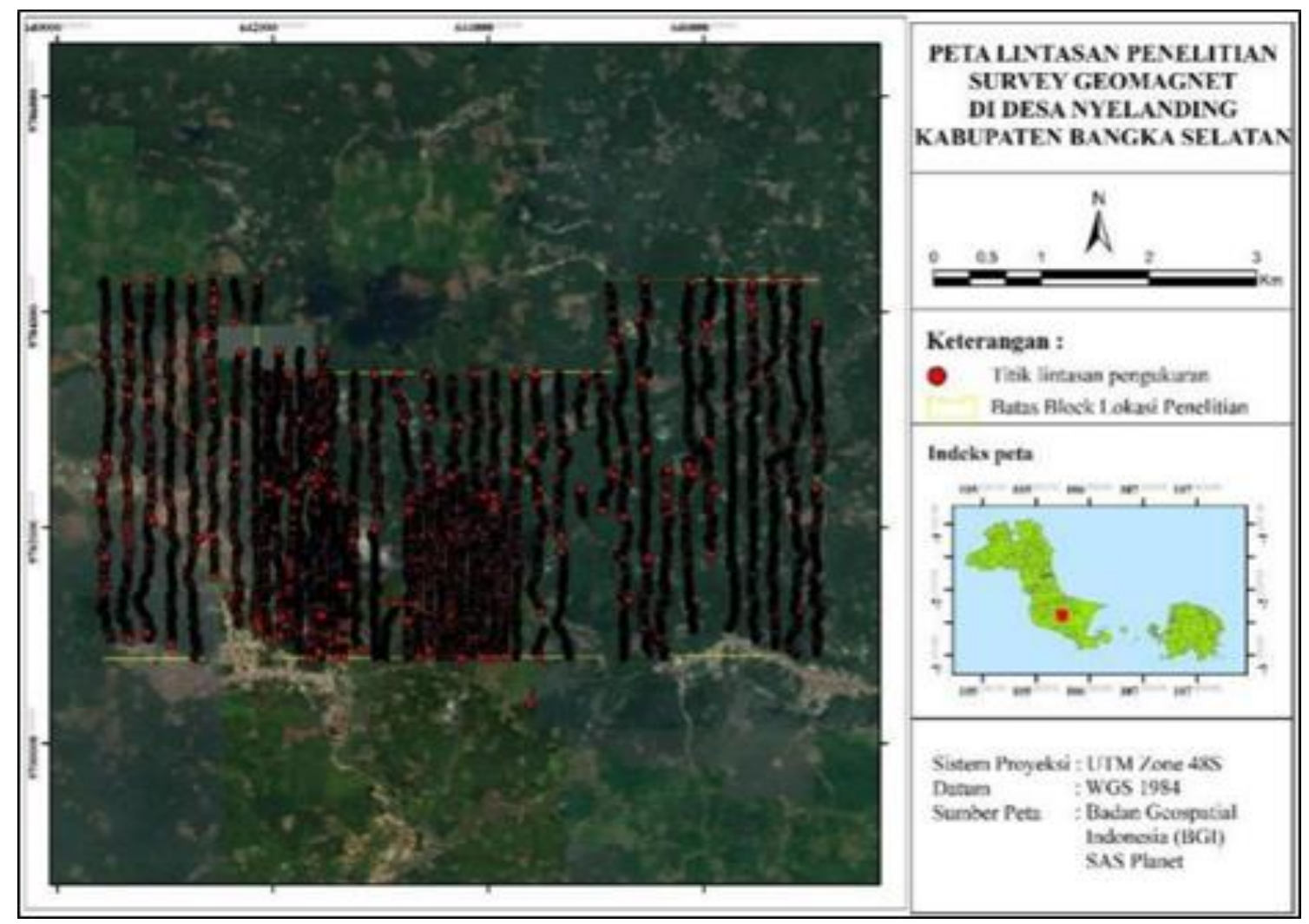

Gambar 1. Peta lintasan survei geomagnet dilokasi penelitian 
penelitian pada Gambar 1, luasan lokasi penelitian $700 \mathrm{~m}^{2}$, akan dibagi menjadi beberapa lintasan pengambilan data geomagnet dengan 1 lintasan sepanjang $\pm 3.5 \mathrm{~km}$ dan jarak spasi antar tiap lintasan adalah $200 \mathrm{~m}$.

\subsection{Metode penelitian}

Penelitian ini menggunakan metode Survey Geomagnetic dengan bantuan alat GSM-19 T Magnetometer, dengan data yang diperoleh yaitu kuat medan magnet, nilai koordinat peta (x,y,z), sampel batuan, hasil sampel XRF, peta geologi, peta kontur, nilai IGRF, nilai inklinasi dan deklinasi. Pengukuran menggunakan metode base-rover (mobile) menggunakan dua buah alat PPM yaitu untuk pengambilan data base dan untuk pengambilan data di lapangan, guna mencatat intensitas medan total dari tiap lintasan. Penelitian ini dimulai dengan aktivitas pengamatan atau observasi, pengukuran, akuisi data dan mapping. Selain itu, pembuatan peta daerah terduga memiliki anomali dengan nilai tinggi menggunakan perangkat lunak Oasis Montaj 8.4. Panjang lintasan yang diukur $\pm 2.5-3.5 \mathrm{~km}$ dengan spasi antar lintasan \pm 200 meter dan pengambilan data mobile dilakukan $3 x$ per stasiun dengan jarak per-stasiun atau satu titik dengan titik lainnya sepanjang 10 meter.

\section{Hasil dan Pembahasan}

\subsection{Kondisi aktual lapangan}

Lokasi penelitian umumnya didominasi dengan batupasir dan batuan metasedimen seperti pada Gambar 2. Hal ini diuji kembali dengan pengambilan sampel sebanyak 4 sampel yang berada di sekitar lokasi penelitian untuk diuji dengan menggunakan XRF ( $x$-ray fluorescent) dengan hasil seperti pada Tabel 1.

Berdasarkan penemuan batuan sampel pada singkapan di lintasan survei, 4 sampel batuan tersebut kemudian diuji di Laboratorium eksplorasi PT. Timah Tbk menggunakan alat XRF portablel vanta, hasilnya secara umum mengandung kadar Sn dan Fe yang cukup besar, hasil pengukuran kadar unsur seperti Tabel 1.

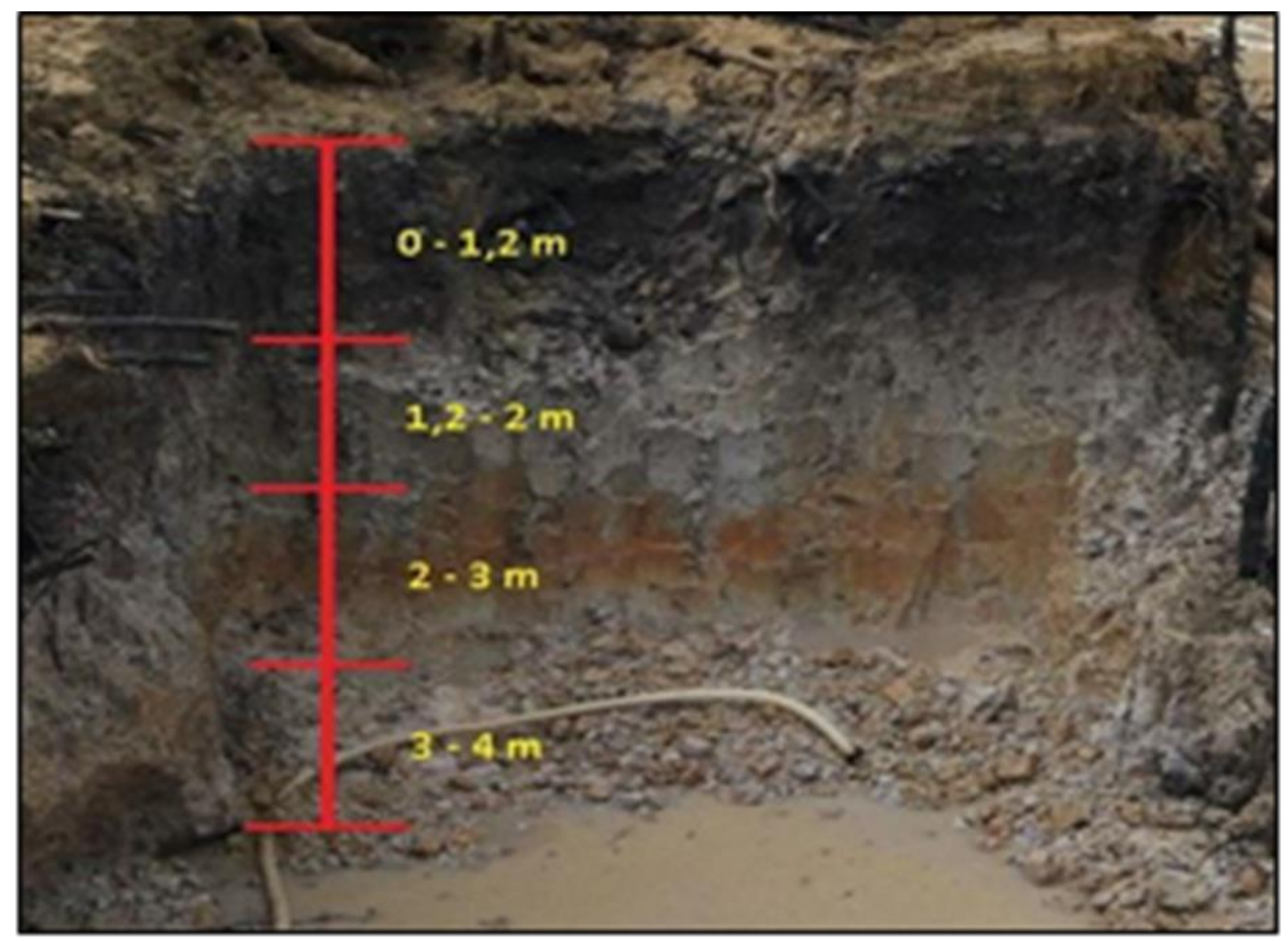

Gambar 2. Singkapan batuan metasedimen pada lokasi 4 berupa lubang galian penambangan warga 
Tabel 1. Hasil pengukuran unsur sampel batuan

\begin{tabular}{lll}
\hline Sampel & Kadar Sn $(\mathrm{ppm})$ & Kadar Fe $(\mathrm{ppm})$ \\
\hline 1 & 1628 & 7433 \\
2 & 135 & 38688 \\
3 & 18 & 9889 \\
4 & 18 & 3732 \\
\hline
\end{tabular}

Hasil analisis unsur sampel menunjukkan jumlah yang signifikan pada sampel 1 , kadar Sn tinggi menunjukkan bahwa keterdapatan mineral cassiterite dominan sedangkan kadar $\mathrm{Fe}$ tinggi menunjukkan proses pelapukan yang dominan. Kandungan mineral oksida besi dalam jumlah yang banyak, dari hasil analisis ini tidak ada hubungan/korelasi antara kehadiran unsur Sn dan Fe. Hasil ini kemudian dikorelasikan dengan hasil pengolahan data magnetik serta koordinat singkapan batuan agar lokasi mineral cassiterite diketahui dan dilakukan overlay di peta persebaran mineralisasi cassiterite di daerah penelitian.

\subsection{Penentuan arah sebaran mineralisasi}

Filter upward continuity memungkinkan untuk melihat kenampakan permukaan, anomali yang disebabkan oleh perumahan/lingkungan yang mengakibatkan nilai magnet sekitarnya tinggi secara drastis dapat teratasi, anomali ini timbul akibat dari benda-benda pada lokasi tersebut memiliki sifat kemagnetan yang tinggi. Rentang upward continuitas yang dilakukan pada penelitian ini ialah 50, 100, 150, 200 dan 250.

Peta upward continuity dengan nilai 50 terlihat daerah zona interest yang menyebar secara acak dan tersebar daerah potensial, anomali rendah magnetik ada di 9 lokasi setelah dilakukannya upward continuity sampai 250 dapat terlihat arah mineralisasi, yang sudah dikerucutkan ke dalam luasan yang lebih kecil. Arah daerah potensial konstan tak berubah sejak ditambahkan nilai inklinasi dan deklinasi pada proses reduce to equator. Hasil pengolahan data tersebut terlihat pada Gambar 3 .

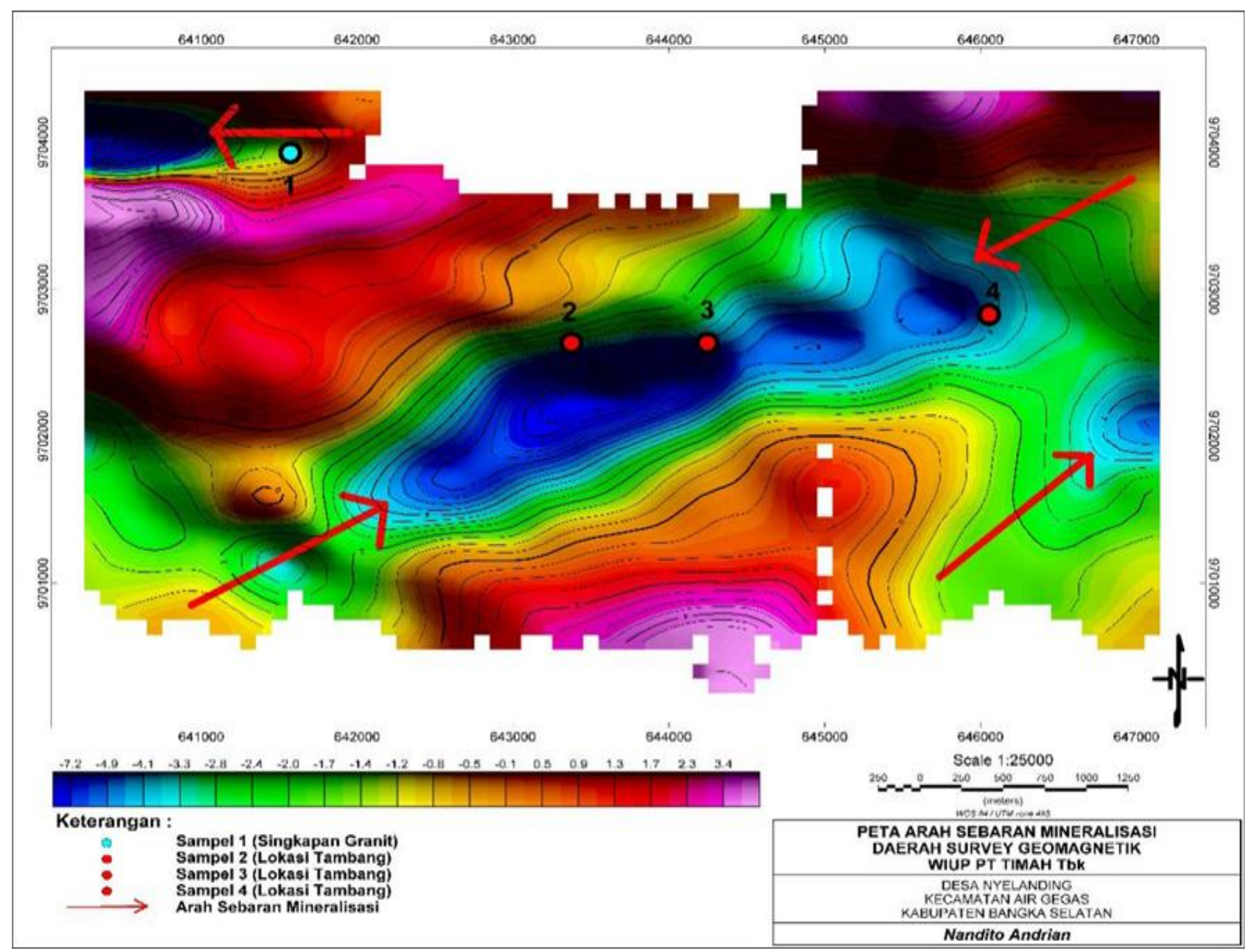

Gambar 3. Peta arah dugaan potensi mineralisasi hasil pengukuran geomagnetik 


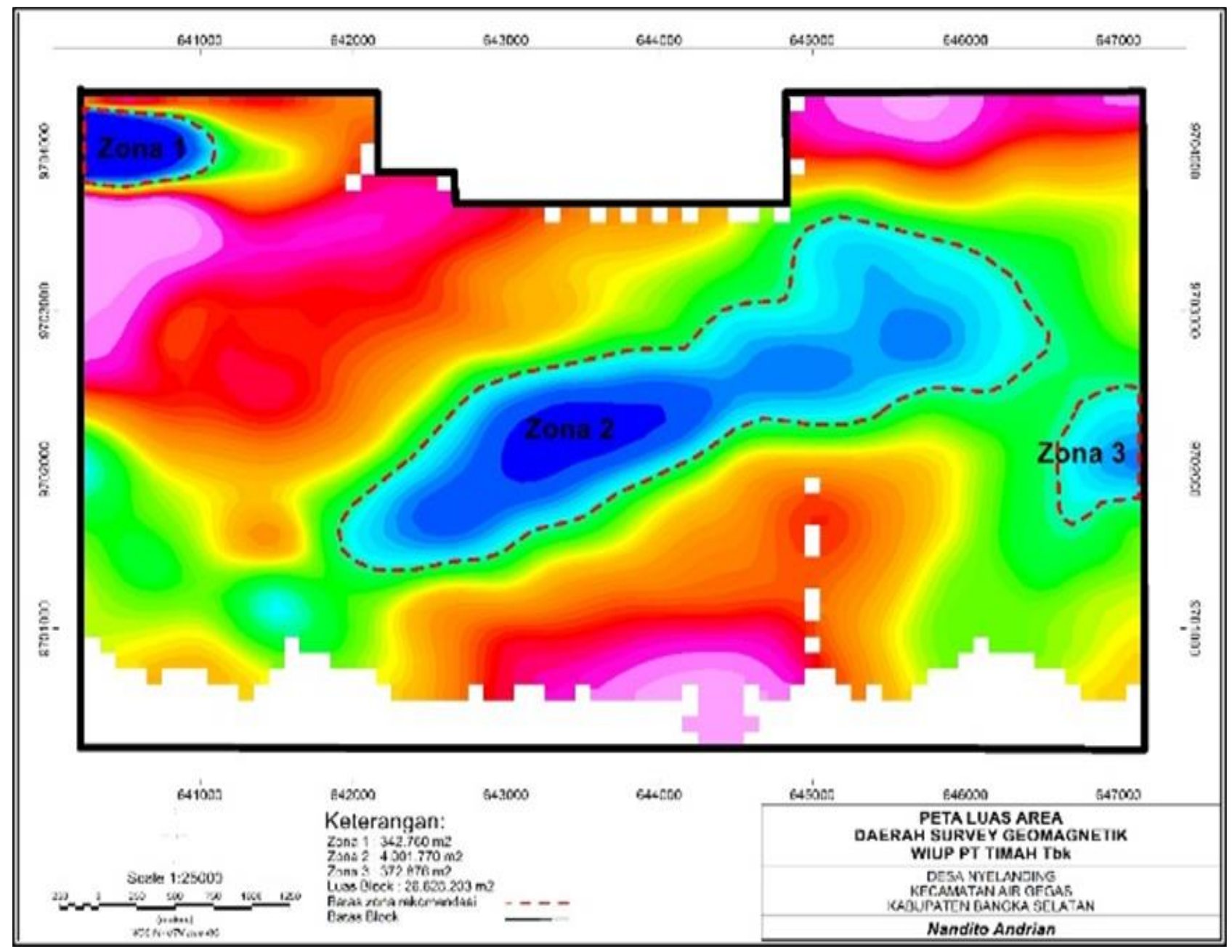

Gambar 4. Peta luasan block dan zona rekomendasi

\subsection{Penentuan daerah rekomendasi dan luasannya}

Hasil penelitian yang menunjukkan daerah potensial menunjukkan anomali magnetik terendah yang terdapat mineral cassiterite berkisar -7.2 sampai -3.3 nT terdapat pada zona 1, 2, dan 3. Daerah rekomendasi untuk penelitian lebih lanjut pada zona 1 dengan luasan $=\left(342.760 \mathrm{~m}^{2}\right)$, zona $2=$ $\left(4001.770 \mathrm{~m}^{2}\right)$, zona $3=\left(372.876 \mathrm{~m}^{2}\right)$ dengan luas total seluruh block penelitian $26.628 .203 \mathrm{~m}^{2}$ (Gambar 4), sedangkan anomali magnetik potensialnya tertinggi berkisar dari 2.3 sampai $3.4 \mathrm{nT}$.

Hasil analisis peta upward continuity 250 dan pencocokan keterdapatan lokasi sampel yang mengandung kadar Sn di sekitar daerah rekomendasi, maka bisa dipastikan terdapat mineral cassiterite di daerah tersebut. Data yang berupa peta ini dapat dijadikan acuan untuk proses selanjutnya seperti pengambilan sampel data bor sampel pada koordinat yang ditentukan dan eksplorasi lanjutan geolistrik untuk mengetahui sebaran mineral cassiterite. Zona potensi dapat dilihat penyebaran pada zona 1, 2, 3 yang direkomendasikan.

\section{Kesimpulan}

Potensi mineralisasi terdapat pada daerah yang memiliki batuan sedimen, dilihat dari uji sampel unsur Sn terdeteksi pada sampel batuan yang mengalami oksidasi. Arah penyebaran mineral untuk Zona 1 berarah dari timur - barat, Zona 2 memfokuskan ke tengah yang berarti dari arah barat daya timur laut atau sebaliknya, Zona 3 dari barat daya - timur laut. Peta upward continuity 250 maka bisa dipastikan daerah tersebut terdapat mineral cassiterite di Zona tersebut yaitu Zona $1=\left(342.760 \mathrm{~m}^{2}\right)$, Zona $2=\left(4001.770 \mathrm{~m}^{2}\right)$, Zona $3=\left(372.876 \mathrm{~m}^{2}\right)$.

\section{Ucapan Terima Kasih}

Penulis mengucapkan terima kasih kepada Fakultas Teknik Universitas Bangka Belitung dan PT Timah Tbk yang telah sangat banyak membantu dalam penelitian di wilayah IUP PT Timah Tbk. 


\section{Referensi}

Guskarnali \& Mardiah. (2018). Mineralization study of Bukit Sambunggiri with the approach of geological and petrogenesys methods in Merawang Subdistrict, Bangka Regency, in: IOP Conference Series: Earth and Environmental Science. Institute of Physics Publishing. doi:10.1088/1755-1315/212/1/012022

Guskarnali \& Mardiah. (2019). Determination Of Geomagnetic Data Measurement Point Spacing By Geostatistic Approach. Atlantis Press. doi:10.2991/icoma-18.2019.16

Hosking, K.F.G. (1988). The World's Major Types of Tin Deposits: Hutchinson, C.S., ed., Geology of Tin Deposits in Asia and the Pacific. International Symposium on the Geology of Tin Deposits, Springer Verlag, New York.

Margono. U, Supandjono, Partoyo. E. (1995). Peta Geologi Lembar Bangka Selatan. Sumatera. Pusat Penelitian dan Pengembangan Geologi

Stemprok, M. (1987). Greisenization (A Review). Geologische Rundschau, 76(1), 169-175.

Sudrajat, D, H. (1996).Geologi Endapan Mineral (Genesa Bahan Galian). Jurusan Teknik Geologi Fakultas Teknologi Mineral ITB, Bandung.

Telford, W.N., Geldard, L.P., Sherrif, R.E., \& Keys, D.A. (1979). Applied Geophysics. Cambridge University Press, Cambridge, London, Newyork, Melbourne. 